\title{
O PIBID FRENTE OS CAMINHOS E DESAFIOS DA FORMAÇÃO DOCENTE PARA A EDUCAÇÃO BÁSICA
}

DOI: http://dx.doi.org/10.5965/198431781112015108

\author{
Alba Regina Battisti de Souza ${ }^{1}$ \\ Lourival José Martins Filho ${ }^{2}$ \\ Débora Picinato ${ }^{3}$ \\ Carolina Paulinha Branco ${ }^{4}$ \\ Júlia Atrib $^{5}$
}

\section{RESUMO}

O artigo é resultado de uma pesquisa sobre a formação docente considerando produções teóricas e políticas de formação, mais especificamente o PIBID - Programa Institucional de Bolsa de Iniciação a Docência. As questões orientadoras são: quais os principais desafios e perspectivas para a docência segundo as produções teóricas em evidência? Como os bolsistas de ID (Iniciação a Docência) percebem as influências do PIBID na sua formação? Quais as possíveis relações entre as premissas teóricas e a efetiva contribuição do PIBID na formação dos licenciandos? Trata de um estudo bibliográfico conjugado com a aplicação de um questionário respondido por dez bolsistas de ID

(Iniciação a Docência). A partir de uma abordagem qualitativa, os dados foram discutidos considerando princípios da análise de conteúdo. Conclui-se que, em vários aspectos, há consonância entre as produções sobre a formação docente e os relatos dos Bolsistas de ID como: maior articulação teoria e prática; reconhecimento mais aprofundado do contexto escolar e, em especial, da sala de aula; construção de saberes específicos para a prática docente, com crescente autonomia e protagonismo.

Palavras-chave: Formação Docente - Prática Pedagógica - Saberes Docentes - Educação Básica PIBID

\footnotetext{
${ }^{1}$ Professora Associada Participante do Departamento de Pedagogia FAED/UDESC Estágio Pós-Doutoral em Educação - UNISINOS/RS - Coordenadora de área -PIBID - Pedagogia - Anos Iniciais do Ensino Fundamental alba.udesc@gmail.com

2 Professor Associado Participante do Departamento de Pedagogia FAED/UDESC e do Programa de Pós Graduação em Gestão da Informação da Udesc. Estagio Pós-doutoral na PUC/PR - Professor Participante PIBID - Pedagogia - Anos Iniciais do Ensino Fundamental - lourivalfaed@gmail.com

${ }^{3}$ Bolsista PIBID - Pedagogia - Anos Iniciais do Ensino Fundamental.

${ }^{4}$ Bolsista PIBID - Pedagogia - Anos Iniciais do Ensino Fundamental.

${ }^{5}$ Bolsista PIBID - Pedagogia - Anos Iniciais do Ensino Fundamental.
} 
THE PIBID FACE CHALLENGES AND WAYS OF TEACHING FOR BASIC EDUCATION

\begin{abstract}
The article is a result of research on teacher training considering theoretical and political productions of training, specifically PIBID - Institutional Program Initiation to Teaching Exchange. The guiding questions are: what are the main challenges and perspectives for teaching second theoretical treatises on evidence? As fellows of ID (Initiation to Teaching) perceive the influences of PIBID in your training? What are the possible relationships between theoretical assumptions and the actual contribution of PIBID the training of undergraduates? Is a bibliographical study in conjunction with

the application of a questionnaire completed for ten fellows ID (Initiation to Teaching). From a qualitative approach, data were discussed considering the principles of content analysis. We conclude that, in many respects, there is consonance between the productions on teacher training and the reports of Fellows of ID such as: greater articulation between theory and practice; further recognition of the school context and in particular the classroom; construction of specific teaching practice with increasing autonomy and leadership knowledge
\end{abstract}

Keywords: Teacher Training - Teaching Practice - Savvy Teachers - Elementary Education - PIBID

Estudos sobre a docência: recorrências e perspectivas

Por muito tempo o ensino foi reconhecido como uma vocação, um apostolado ou um sacerdócio leigo; seu exercício tinha como base as qualidades morais que o bom mestre deveria ter. Nas últimas décadas, com o processo de massificação do ensino houve um movimento em prol do reconhecimento da docência como ofício. E, mais recentemente há uma tendência em considerar o ensino na lógica da profissionalização. As três concepções vocação, ofício e profissão - exprimem uma linha de evolução do ensino, porém com maior ou menor grau, estão presentes na contemporaneidade (TARDIF e LESSARD, 2008).

Para Nóvoa (2009) na atualidade os professores retornaram ao centro das atenções, reparecem no século XXI, depois de quase quarenta anos de relativa invisibilidade "como elementos insubstituíveis não só na promoção das aprendizagens, mas também na construção 


\section{EDUCAÇÃO, ARTES}

VOLUME 11, NÚMERO 1, Ano 2015

E INCLUSÃO

ISSN 1984-3178

de processos de inclusão que respondam aos desafios da diversidade e no desenvolvimento de métodos apropriados de utilização das novas tecnologias." (p. 13)

As práticas docentes são constituídas por um conjunto de valores, princípios, conhecimentos e atitudes histórica e socialmente situadas incluindo a trajetória pessoal dos professores, experiências construídas, espaço e contexto no qual atuam. As relações constituídas nos espaços de formação muitas vezes representam uma referência importante para o futuro professor, mesmo que em vários momentos sejam apontadas contradições e descontentamentos em muitos outros, a forma dos professores organizarem e desenvolverem suas aulas, de realizarem as avaliações e de se comunicarem, são referências significativas. Essa dimensão humana é inerente à função docente e segundo Tardif e Lessard (2007, p. 268) “Componentes como o calor, a empatia, a compreensão, a abertura de espírito, o senso de humor, etc. constituem, assim, trunfos inegáveis do professor enquanto trabalhador interativo."

Os dilemas sobre a docência, que buscam compreender sua constituição epistemológica, pedagógica e histórica, são evidentes e ainda carecem de muitos elementos para se tornar reconhecida como um campo constituído por saberes próprios. Para Nóvoa (2008) ainda há uma tendência em considerar que basta dominar bem a matéria de ensino e ter certa aptidão de comunicação para ser professor/a, o que leva a perda de prestígio da profissão e a ausência de um status de cientificidade.

Esta questão no âmbito das universidades e especialmente Faculdades de Educação, passa, sobretudo por repensar a estrutura departamental que torna os currículos tão engessados e hierarquizados que a questão da formação docente e da infância é muitas vezes suprimida pela própria estrutura burocrática criada em torno dos docentes universitários. Pensar a formação docente para a infância nas universidades vai exigir também que os professores das instituições de ensino superior tenham humildade de transpor as fronteiras de suas disciplinas, no sentido de dialogarem sobre as necessidades formativas tão presentes no contexto dos professores da Educação Básica.

Paulo Freire (1992) alertou da necessidade do docente em qualquer nível e modalidade de ensino fazer de sua atuação um espaço de aprendizagem e cumplicidade. A formação 


\title{
EDUCAÇÃO, ARTES
}

VOLUME 11, NÚMERO 1, Ano 2015

E INCLUSÃO

ISSN 1984-3178

inicial no âmbito dos cursos de Pedagogia precisa oportunizar discussões que estão pulsantes no contexto das políticas e práticas produzindo conhecimentos por meio de ações de pesquisa e extensão não apenas para reafirmar tais políticas e práticas, mais sobretudo para colocá-las em cheque.

Por outro lado, é inegável o progresso na busca do reconhecimento dos saberes da docência, compostos por várias dimensões e elementos; na ação, esses são mobilizados, articulados e reconstruídos num movimento peculiar, contínuo e dinâmico. E é nas instituições escolares que sua essência se manifesta com mais intensidade:

\begin{abstract}
O trabalho escolar tem duas grandes finalidades: por um lado, a transmissão e apropriação dos conhecimentos e da cultura; por outro lado, a compreensão da arte do encontro, da comunicação e da vida em conjunto. É isto que a Escola sabe fazer, é isto que a Escola faz melhor. É nisto que ela deve concentrar as suas prioridades, sabendo que nada nos torna mais livres do que dominar a ciência e a cultura, sabendo que não há diálogo nem compreensão do outro sem o treino da leitura, da escrita, da comunicação, sabendo que a cidadania se conquista, desde logo, na aquisição dos instrumentos de conhecimento e de cultura que nos permitam exercêla (NÓVOA, 2009, p.62-63).
\end{abstract}

O nível de complexidade que envolve a docência é elevado, o/a professor/a está constantemente diante de urgências e incertezas. Para Perrenoud (2001), a urgência se refere à necessidade de compreender a dinamicidade de um sistema complexo, no qual o docente tem que agir, tomar decisões, fazer encaminhamentos cujos resultados são marcados pelas incertezas.

Segundo Cunha (2004) a complexidade na docência está na necessidade de uma preparação cuidadosa, com singulares condições de exercício, o que a distingue de várias outras profissões. Assim "ser professor não é tarefa que qualquer um faz, pois a multiplicidade de saberes e conhecimentos que estão em jogo na sua formação, exige uma dimensão de totalidade, que se distancia da lógica das especialidades, tão cara a muitas outras profissões $[\ldots] ”(p .41)$

Para Gómez (1997) as situações com as quais o educador se depara são únicas, não existe um caso-problema para cada conhecimento profissional não podendo ser resumido à mera aplicação de regras e procedimentos já consagrados, dessa forma é importante que tenha 


\title{
EDUCAÇÃO, ARTES
}

oportunidade de aprender a construir e comparar novas estratégias de ação, novas fórmulas de pesquisa, novas teorias e novos modos de definir e enfrentar os problemas.

Esta preocupação parte da premissa de Paulo Freire (1974) que o mundo não é, o mundo está sendo. Neste sentido, a história e o ser humano e as práticas pedagógicas não podem ser vistos numa visão determinista, absoluta ou fatalista. É a esperança sempre crítica e engajada que define o fazer docente para além de uma atividade neutra e sem compromisso.

Nesse sentido, a docência está em contínua transformação, não havendo regularidades na ação docente, mesmo compreendendo as rotinas do ambiente escolar e acadêmico, é impossível repetir processos na mesma intensidade e significado. Os docentes aprendem com o que fazem e usam esses saberes para propor novas experiências podendo até guardar elementos das anteriores, mas sempre ressignificadas no novo contexto (CUNHA, 2004).

No entanto também é importante destacar a dimensão que os discursos sobre a formação docente foram tomando ao longo dos últimos anos e ao mesmo tempo se dissipando em função das poucas mudanças provocadas. Tardif (2000), traduz uma das preocupações com relação aos profissionais que atuam na formação inicial do professor:

\begin{abstract}
Na universidade, temos com muita frequência a ilusão de que não temos práticas de ensino, que nós mesmos não somos profissionais do ensino ou que nossas práticas de ensino não constituem objetos legítimos para a pesquisa. Esse erro faz que evitemos os questionamentos sobre os fundamentos de nossas práticas pedagógicas, em particular nossos postulados implícitos sobre a natureza dos saberes relativos ao ensino. Não problematizada, nossa própria relação com os saberes adquire, com o passar do tempo, a opacidade de um véu que turva nossa visão e restringe nossas capacidades de reação (TARDIF, 2000, p 17).
\end{abstract}

Sobre a relação escola e universidade Nóvoa (2009) alerta:

Muitas vezes, e isto é um problema de fundo as instituições de formação de professores, ignoram ou conhecem mal a realidade das escolas, especialmente do ensino fundamental. É fundamental assegurar que a riqueza e a complexidade do ensino se tornem visíveis, do ponto de vista profissional e científico, adquirindo um estatuto idêntico a outros campos de trabalho acadêmico e criativo. E, ao mesmo tempo, é essencial reforçar dispositivos e práticas de formação de professores baseadas numa investigação que tenha como problemática a ação docente e o trabalho escolar (NÓVOA, 2009, p.22). 


\section{EDUCAÇÃO, ARTES}

Em meio a todas as exigências sociais, de caráter amplo, há um conjunto de condicionantes específicos dos ambientes nos quais os docentes atuam, caracterizados por aspectos estruturais, administrativos e pedagógicos, somados às variáveis do espaço onde ocorre efetivamente a docência, acrescendo-se as características socioculturais e as expectativas do grupo de alunos/as.

Ser docente requer uma formação longa e continua fundamentada na autonomia do fazer pedagógico no ambiente escolar, enfrentando problemas decorrentes da realidade profissional na tomada de decisão na superação dos mesmos e, sobretudo, na avaliação de suas consequências.

Além da autonomia e da compreensão da realidade, a instrumentalização do conhecimento no desenvolver de ações de formação podem fomentar a aquisição de teorias que constituem referenciais para subsidiar a intervenção docente, pois suas ações resultam de um movimento dialético entre teoria e prática, que mutuamente confrontam-se e complementam-se na direção de avançar no conhecimento, além de subsidiar alternativas na própria ação de intervenção. Segundo Nóvoa é preciso uma dinâmica na qual o professor se integre ativamente:

Trata-se, sim, de afirmar que as nossas propostas teóricas só fazem sentido se forem construídas dentro da profissão, se forem apropriadas a partir de uma reflexão dos professores sobre o seu próprio trabalho. Enquanto forem apenas injunções do exterior, serão bem pobres as mudanças que terão lugar no interior do campo profissional docente. (NÓVOA, 2009, p. 19)

Assim, pressupor a reflexão como algo inerente à docência significa reconhecê-la articulada a uma constante análise e fundamentação teórica e a um contínuo processo de redimensionamento no qual o educador é agente fundamental. Zeichner (2008) destaca que a formação reflexiva deveria estar conectada a lutas mais amplas por justiça social e contribuir para a diminuição das lacunas na qualidade da educação disponível para estudantes de diferentes perfis, em todos os países do mundo. Ao revisitar o conceito do qual foi um dos mentores, diz ser fundamental criar alternativas para que os professores possam refletir sobre 


\title{
EDUCAÇÃO, ARTES
}

suas próprias situações de vida, para tomarem a direção de sua trajetória docente. O que é uma tendência praticamente consolidada em termos de pesquisa sobre a formação docente tendo como recorrência em outras propostas, o professor como importante agente. Souza (2008) ilustra essa ideia:

\begin{abstract}
Pesquisas com histórias de vida no campo educacional evidenciam a pessoa do professor, ao ressaltar a relevância da subjetividade como um dos conceitos articuladores dos questionamentos teóricos vigentes e das propostas que realizam o estudo do método. Novos conceitos para a compreensão do trabalho docente surgiram com os estudos educacionais, cujas abordagens de pesquisa passaram a reconhecer o professor como sujeito, trazendo à tona a necessidade de investigar os saberes de referencia dos professores sobre suas ações e pensamentos caracterizando-os inclusive, como sujeitos de um saber e de um fazer inerentes a profissão (SOUZA, 2008, p.144).
\end{abstract}

Para Tardif (2002), os professores só serão reconhecidos como sujeitos do conhecimento quando lhes concedermos, dentro do sistema escolar e dos estabelecimentos, o status de verdadeiros atores, e não o de simples técnicos ou de executores das reformas da educação concebidas com base numa lógica burocrática e afirma: "Pessoalmente, não vejo como posso ser um sujeito do conhecimento se não sou, ao mesmo tempo, o ator da minha própria ação e autor do meu próprio discurso" (2002, p.243).

Sendo assim, faz sentido tecermos uma defesa a ampliação do repertório de conhecimentos tanto de âmbito teórico como prático nos processos de formação de professores. Acreditamos que a ampliação do universo cultural, intelectual e humano dos professores possibilita que suas práticas se aproximem cada vez mais das demandas sociais que vão se apresentando ao longo de sua profissão e permitem que a reflexão crítica se instale em suas práticas cotidianas. É neste sentido que a abordagem histórico-social nos ajuda compreender o contexto em que a formação de professores atualmente está calcada, já que em sua perspectiva, para se entender o contexto é necessário buscar compreender o processo histórico que o envolve.

Desse modo, se por um lado, não podemos negar os avanços teóricos, políticos, científicos e pedagógicos no campo da educação, principalmente no que tange a formação dos professores, por outro lado, temos que ficar atentos e para não cairmos na ingenuidade de 


\section{EDUCAÇÃO, ARTES}

VOLUME 11, NÚMERO 1, Ano 2015

aplaudi-los sem uma análise teórica e crítica profunda entre os objetivos propostos, os interesses proclamados e as reais condições de realização dos mesmos.

A prática docente é composta por diferentes saberes (TARDIF, 2002): saberes da formação profissional, saberes disciplinares, saberes curriculares e saberes experienciais. Este último, os saberes experienciais ou práticos, referem-se aos saberes oriundos das experiências e por ela são validados. Questões do ambiente de trabalho, em especial as condições na quais os docentes atuam têm sido uma preocupação, como demonstram Tardif e Lessard (2007), ao citar fatores que interferem no trabalho:

a) Fatores ambientais e materiais: natureza dos lugares de trabalho, recursos materiais disponíveis ou não, dependência de transportes.

b) Fatores sociais: localização da escola, situação socioeconômica dos alunos, índice de violência no entorno da escola.

c) Fatores ligados ao "objeto de trabalho": tamanho e diversidade das turmas, idade dos alunos, presença de alunos com necessidade especiais.

d) Fenômenos resultantes da organização do trabalho: tempo de trabalho, número de matérias a lecionar, vínculo empregatício, diversidade das tarefas, tempo pessoal disponibilizado as atividades de ensino.

e) Exigências formais ou burocráticas a cumprir: horários, avaliações, reuniões com os pais, reuniões e tarefas obrigatórias.

f) Aliado a esses fatores, o modo como os docentes lidam com esses aspectos e as estratégias que criam para conviver ou não com eles.

Em meio a tantos estudos e discussões sobre a formação e prática docente, destacam-se o reconhecimento da docência como uma atividade complexa e propostas de formação que priorizem a relação teoria e prática por meio de aproximações dos licenciando do contexto escolar de forma crítica e propositiva. Assim, entendendo o PIBID como uma iniciativa que tem entre seus objetivos essas premissas, considera-se que as experiências dos bolsistas de ID podem fornecer elementos para analisar as repercussões do programa e identificar aspectos que possam contribuir com os cursos de licenciatura. 


\section{O PIBID no contexto das discussões e ações sobre a formação docente}

O Programa Institucional de Bolsa de Iniciação a Docência (PIBID) criado em novembro de 2007 e esta vinculado a CAPES (Coordenadoria de Aperfeiçoamento de Pessoal de Nível Superior) tem entre seus objetivos segundo o Edital 01/2011 e Portaria 260 de dezembro de 2010: elevar a qualidade da formação inicial de professores nos cursos de licenciatura, promovendo a integração entre a Educação Superior e a Educação Básica ; inserir os licenciandos no cotidiano de escolas da rede pública de educação; incentivar escolas públicas mobilizando seus professores como co-formadores dos futuros docentes e tornandoas protagonistas nos processos de formação inicial para o magistério; contribuir para a articulação entre teoria e prática à formação dos docentes. De forma geral, os objetivos e premissas são consonantes às atuais perspectivas de formação docente, mas também trazem a tona indagações sobre as reais repercussões na formação de novos docentes.

Diante disto, a partir da análise de um questionário respondido por dez bolsistas de iniciação da docência (ID) - do Curso de Pedagogia (Foco nos Anos Iniciais) - busca-se interpretar - com base em princípios da análise de conteúdo (BARDIN, 2009; FRANCO, 2003) de que forma o programa tem sido vivenciado e percebido, com destaque para as principais aprendizagens proporcionadas; possíveis reflexões sobre o curso de Pedagogia que frequentam; desafios da escola pública sobre a perspectiva dos futuros docentes; expectativas de continuidade ou não na carreira docente. Estes questionários se configuram em documentos, pois fizeram parte do processo de avaliação do Programa, aplicados pelos coordenadores de área. Os trechos dos questionários são identificados pela letra $\mathrm{R}$ (Respondente) seguida por um número correspondente.

\section{Vivências e interpretações dos Bolsistas ID}

Quais as principais aprendizagens o programa tem lhe proporcionado? Eis uma das perguntas-chave do questionário. Afinal, o que as bolsistas afirmam ter aprendido com relação ao exercício da docência? Eis algumas manifestações: 


\section{EDUCAÇÃO, ARTES}

VOLUME 11, NÚMERO 1, Ano 2015

E INCLUSÃO

ISSN 1984-3178

"Através do programa estou tendo a oportunidade de entender a importância e a necessidade que o professor tem de planejar suas aulas, bem como de adapta-lo já que nem sempre as coisas saem como foi esperado, por isso o professor tem que ser dinâmico e flexível em suas ações. Além disso, o PIBID tem me feito pensar em uma educação que faça os alunos refletirem, se tornarem seres críticos, dai se dá a importância de nunca dar respostar prontas aos educandos, e sim fazê-los buscar suas próprias conclusões.” (R2)

Essa convivência com a dinâmica da escola, da sala de aula e do trabalho docente no cotidiano da escola, aproxima o bolsista ID de um contexto no qual irá atuar, possibilitando a compreensão de princípios e conceitos com os quais tem acesso num âmbito teórico na graduação, como planejamento, e acompanhamento do processo de aprendizagem. Nessa direção a próxima respondente corrobora:

Com a minha participação no PIBID eu consigo compreender melhor o funcionamento de uma unidade escolar, do trabalho desenvolvido com turmas de anos iniciais, bem como, conciliar os conhecimentos teóricos vistos na faculdade com as práticas pedagógicas dos profissionais atuantes, além de propor atividades diversificadas com o objetivo de contribuir na aprendizagem dos alunos. Também é possível refletir sobre que tipo de profissional eu quero ser e sobre os desafios da profissão docente na atualidade. (R5)

O contato mais direto e contínuo com o professor que atua na sala de aula, merece atenção. Em geral a pessoa referência nos processos de formação em campo, como nos estágios, é um docente de graduação, responsável em coordenar e orientar todas as etapas. O PIBID ao incluir os professores da escola no programa, como co-formadores, os imbui de outra responsabilidade, para além de "receber" os licenciandos, pois criam uma relação com os bolsistas que os valoriza muito mais.

"O PIBID também traz aprendizagens nos momentos que estamos em sala de aula e visualizamos como a professora regente da turma explica tal conteúdo aos alunos, qual a metodologia utilizada, etc. Também experimentamos situações de aprendizado quando ajudamos as crianças na realização de atividades e, ainda, quando levamos para elas atividades preparadas por nós bolsistas. Nesses momentos 


\section{EDUCAÇÃO, ARTES}

VOLUME 11, NÚMERO 1, Ano 2015

E INCLUSÃO

sentimos o quanto é significativo esse momento de aprendizagem para os alunos, o quanto eles tem "fome" de perguntas, dúvidas, afirmações; desse jeito percebemos que além de ensinar, também aprendemos. (R4)

Quanto às aprendizagens, destacam a compreensão do funcionamento da escola, do trabalho nos anos iniciais, do planejamento das aulas e da atitude do professor diante das novidades que possam ocorrer:

Reconhecer a docência como uma atividade pautada também na reflexão, na discussão e trabalho coletivo também é um importante exercício, ao que demonstram os bolsistas:

Por último e não menos importante, sinto que também acontece o aprender durante as reuniões na nossa instituição de ensino, juntamente com a professora coordenadora do projeto e as demais colegas, visto que nessas ocasiões preparamos materiais pedagógicos, ouvimos e falamos da nossa experiência e da experiência do outro." (R4)

"Acredito que, primeiramente, nos é proporcionado o conhecimento do 'caminhar' da escola e dos seus profissionais. Participamos, por exemplo, de reuniões pedagógicas que abordam assuntos de ordem burocrática, como a decisão do calendário escolar, datas de festas temáticas e entregas de boletim, etc. Por outro lado, também nessas reuniões e em outros momentos, temos a possibilidade de participar de formações pedagógicas que trazem novos conhecimentos e nos enriquecem com experiências. Além disso, $(R 7)$

Os bolsistas também foram indagados se o contato com a escola tem provocado reflexões sobre o curso de Pedagogia. Demonstram preocupação com a interação teoria e prática no curso e revelam que o programa possibilita mais preparo para a carreira profissional:

Sim, acredito que a principal reflexão está no fato de que há no curso pouca relação com a prática, muito se fala em teoria, teóricos da educação, porém a prática é pouco abordada. E diante disso, quando entramos em uma sala de aula, nos sentimos completamente ansiosos, despreparados. Então, este é mais um dos motivos que acredito que o 


\section{EDUCAÇÃO, ARTES}

VOLUME 11, NÚMERO 1, Ano 2015

E INCLUSÃO

ISSN 1984-3178

PIBID faça a diferença, pois graças ao programa pude ter este contato, e sei que mais adiante quando entrar em uma sala de aula como professora saberei dos reais desafios existentes e como devo enfrenta-los. (R2)

Sim, o contato com a escola veio destacar que o curso deve proporcionar aos seus estudantes um contato mais direto com a prática, como acontece no PIBID, por exemplo, pois assim será possível relacionar as teorias exploradas na faculdade de acordo com o real contexto existente nas escolas. (R3)

O contato com a escola sem dúvida tem me levado a refletir sobre meu curso em Pedagogia, pois muitas vezes tenho a sensação de que se não fosse pelo PIBID, eu pouco conheceria sobre a prática educacional. Isso porque, teoria não nos falta no curso, porém, a prática é escassa. Somente nas disciplinas de Pesquisa e Prática Pedagógica temos o contato com as instituições de ensino, mas mesmo assim, esse período é muito curto e não nos satisfaz, pois quando estamos quase nos familiarizando com o espaço e as pessoas, nosso tempo com eles acaba. (R4)

O contato com a escola e, mais especificamente, com a educação pública me faz refletir constantemente acerca de muitos aspectos estudados ao longo do curso de Pedagogia. Consigo perceber a importância da formação continuada para o aprimoramento do trabalho dos educadores; a importância (ou a falta!) de políticas públicas direcionadas para a educação e para proporcionar melhor condições de trabalho aos professores e melhores condições de aprendizagem aos alunos; a necessidade de um contato mais profundo com as instituições escolares, no caso de estudantes de Pedagogia em formação. (R5)

Os cursos de licenciatura em geral se limitam com a formação docente por meio de estágios curtos e pontuais e se eximem da responsabilidade com o egresso, ou quando muito aplicam pesquisas sobre o papel da graduação na sua formação. Ir para além da constatação das dificuldades dos ingressantes, significa também pensar e propor uma formação mais próxima do contexto de atuação propiciando um real convívio dos licenciandos com o cotidiano da cultura escolar o mais cedo possível. Nóvoa traz algo interessante sobre a realidade dos docentes "iniciantes":

Um momento particularmente sensível na formação de professores é a fase de indução profissional, isto é, os primeiros anos de exercício docente. Grande parte da 


\section{EDUCAÇÃO, ARTES}

nossa vida profissional joga-se nestes anos iniciais e na forma como nos integramos na escola e no professorado. Neste sentido, este momento deve ser organizado como parte integrante do programa de formação em articulação com a licenciatura e o mestrado (NÓVOA, 2009, p. 38).

Outra questão foi sobre como percebem a relação entre as políticas públicas para a educação básica e as reais condições de trabalho dos professores:

O contato com a escola e, mais especificamente, com a educação pública me faz refletir constantemente acerca de muitos aspectos estudados ao longo do curso de Pedagogia. Consigo perceber a importância da formação continuada para o aprimoramento do trabalho dos educadores; a importância (ou a falta!) de políticas públicas direcionadas para a educação e para proporcionar melhor condições de trabalho aos professores e melhores condições de aprendizagem aos alunos; a necessidade de um contato mais profundo com as instituições escolares, no caso de estudantes de Pedagogia em formação. (R5)

Os depoimentos indicam que a inserção na escola durante a graduação possibilita o contato com a profissão e assim conhecer a grande diversidade de questões, problemas e possibilidades do trabalho docente. Para Tardif e Lessard (2008, p. 61)

[...] os saberes que servem de base para o ensino, tais como são vistos pelos professores, não se limitam a conteúdos bem circunscritos que dependem de um conhecimento especializado. Eles abrangem uma grande diversidade de objetos, de questões, de problemas que estão todos relacionados com seu trabalho. Além disso, não correspondem, ou pelo menos muito pouco, aos conhecimentos teóricos obtidos na universidade e produzidos pela pesquisa na área de Educação: para os professores de profissão, a experiência do trabalho parece ser fonte privilegiada de seu saberensinar (TARDIF e LESSARD, 2008, p. 61).

Para Tardif e Lessard (2008) as experiências realizadas durante a formação levam não somente a compreender o sentido da escolha da profissão, mas influenciam na orientação e nas práticas pedagógicas atuais dos professores e professoras. Para o autor a socialização profissional permite na medida em que são incorporadas atitudes e comportamentos, perceber melhor a dimensão historicamente construída dos saberes, do saber-fazer e do saber-ser e fundamentar a prática do professor, o que ele é e faz em sua história profissional. 


\section{EDUCAÇÃO, ARTES}

VOLUME 11, NÚMERO 1, Ano 2015

E INCLUSÃO

ISSN 1984-3178

Sobre os principais desafios e perspectivas, questionam os rumos da educação, e demonstram compromisso de repensar a prática pedagógica:

Assumir a escola como um espaço político, de exercer a cidadania; olhar para os estudantes e entendê-los dentro de todo um contexto que envolve sua história, a família e suas condições econômicas e sociais; estar atento aos conflitos internos presentes no dia a dia da escola, a precarização da profissão, o compromisso de repensar a prática pedagógica para melhoria e qualidade de ensino. (R6)

Outra preocupação é sobre a política de educação inclusiva. Torna-se evidente a distância entre o discurso de inclusão e sua real prática:

Penso que o principal desafio está ligado à educação especial. Muitos têm a visão de que a educação especial nas escolas (tanto públicas como privadas), de que ela é só inclusiva. Na minha visão a educação especial não está conectada a somente isso. É um espaço de aprendizagem dos conteúdos sim, para essas crianças com necessidades especiais. É um descaso com essas crianças, observei muitas vezes essas crianças serem deixadas de lado, pois não há atividades voltadas para suas necessidades. Penso que esse aspecto é um dos principais desafios das escolas públicas. (R8)

Faz-se necessário que os docentes busquem exercer um trabalho voltado para e com os alunos, aliando os conteúdos curriculares aos conhecimentos e às experiências das crianças, mas para isto também é necessário de estrutura e materiais apropriados. De acordo com Nóvoa (2009):

As perguntas sucedem-se. Será que, hoje, muitos professores não são bem menos reflexivos (por falta de tempo, por falta de condições, por excesso de material didático pré-preparado, por deslegitimação face aos universitários e aos peritos) do que muitos dos seus colegas que exerceram a docência num tempo em que ainda não se falava do "professor reflexivo"? Numa palavra, não vale a pena repetir intenções que não tenham uma tradução concreta em compromissos profissionais, sociais e políticos ( NÓVOA, 2009, p.22). 


\section{EDUCAÇÃO, ARTES}

VOLUME 11, NÚMERO 1, Ano 2015

E INCLUSÃO

ISSN 1984-3178

O período inicial na docência é difícil e crítico, sobretudo devido à estrutura e organização da instituição agravado pela falta de experiência e à ausência de um acompanhamento sistematizado.

Ao mesmo tempo em que tenho vontade de estar dentro das instituições para poder mudar algumas práticas exercidas, tenho anseio de, após alguns anos, estar decepcionada com a realidade da educação e perceber que é uma luta "vencida". (R9)

Mesmo com muita ciência das condições professores na Educação Básica na atualidade, grande parte das bolsistas pretende permanecer na área da educação e existe uma preocupação sobre "como" atuar na docência diante de tantos desafios:

"Sim. Tenho uma grande vontade em continuar trabalhando em sala de aula. Apesar de que algumas vezes desanima alguns atos $e$ contradições no âmbito educacional; o ato de ser docente, de ensinar e ter contato com a escola e com os alunos me encoraja e me incentiva para a realização de importantes trabalhos. Penso que o mínimo que eu faça, mas com carinho, dedicação e comprometimento irá resultar de forma positiva no processo de ensino aprendizagem dos alunos." (R7)

A compreensão da docência integrada a um contexto escolar e a necessidade do trabalho coletivo, da cooperação, faz-se presente na interpretação da bolsista ID que também pretende continuar na carreira (R10):

"Sim, ainda não decidi qual área, gosto de séries iniciais e orientação educacional, mas o PIBID está sendo decisivo na minha escolha, pois estou ciente da realidade escolar, e o fundamental é saber que posso fazer a diferença se optar por qualquer uma dessas opções, o PIBID tem me mostrado que o professor não é responsável e nem consegue fazer tudo sozinho, e que para fazer a diferença precisa que o coletivo coopere, trabalhe em conjunto, e o principal conjunto são os envolvidos na escola e a família." 
Os depoimentos revelam também muito compromisso e reconhecimento do papel docente na vida de uma criança, buscam uma "[...] humana docência, onde ser educador é ser o mestre de obras do projeto arquitetado para sermos humanos" (ARROYO, 2000, p.41), como podemos constatar: "Pretendo fazer com que os alunos se sintam bem na escola, e não tenham mais o olha que escola é 'ruim', 'chata', e sim que vejam a importância dessa instituição e assim sejam agentes das suas vidas."(R8)

\section{Considerações finais}

Junto ao trajeto teórico delineado sobre a formação e prática docente - considerando os avanços até agora conquistados e as contradições e dúvidas ainda presentes - fez-se um esboço teórico das perspectivas para formação docente, segundo diversos autores e conjugando com depoimentos de bolsistas de ID do PIBID.

As colocações de Tardif e Lessard (2007) evidenciam o lugar tomado pela docência entre os diversos pesquisadores da atualidade. Há uma preocupação em compreender o processo de organização docente, suas implicações e o papel dos agentes de formação.

As análises demonstram um significativo avanço no âmbito das pesquisas sobre a docência sendo possível identificar algumas tendências mais veiculadas, como: compreensão da docência em sua complexidade e dinamicidade; a ideia do protagonismo docente, a necessidade de uma articulação mais efetiva entre escola e universidade (agências formadoras). A importância da profissionalidade docente permeia os estudos, numa tentativa constante de ressaltar que esse processo exige conhecimentos específicos e legitimados academicamente.

Aprendemos também com Martins Filho (2006) que no processo de produção de conhecimentos incluímos o processo de humanização - o processo de produção dos sujeitos. Assim, na busca de compreender as crianças e os adultos como protagonistas do processo educacional, consideramos como essencial entender as intricadas relações entre o meio como fonte de humanização e os sujeitos em uma perspectiva ativa que percebem significados e atribuem sentidos ao que vivem, e o professor, com um papel substancial de mediador e criador de mediações que apresenta para as crianças o mundo da cultura que se abre cada vez 


\section{EDUCAÇÃO, ARTES}

VOLUME 11, NÚMERO 1, Ano 2015

E INCLUSÃO

ISSN 1984-3178

mais para elas. As pessoas em processo de aprendizagem apresentam-se nesse processo como sujeitos que produzem ação, uma produção que na maioria das vezes é resultado da interação com o coletivo.

A ideia das interações humanas desenvolvida por Tardif (2002) nos apresenta um requisito essencial para interligarmos a nossa análise da organização do trabalho pedagógico, qual seja: - trabalhar em prol da coletividade, reciprocidade e da aprendizagem relacional. No qual seja possível pensarmos em processos educacionais que compartilham experiências, ampliando os saberes por meio do diálogo e da parceria mútua entre os diversos sujeitos participantes do processo. Pensar nas relações sociais como eixo central para o exercício do trabalho pedagógico, é trazer algumas sendas para novas atribuições no que se refere a prática educacional dos professores, bem como redefinir a função social das instituições de Educação Básica

Neste caminhar os autores que postulam as novas tendências de formação docente, em geral advogam que as avaliações dos grandes projetos têm demonstrado que alteram pouco as coordenadas básicas do sistema educativo, concretizadas nas escolas, quando não há o envolvimento efetivo dos docentes, pois se espera que transformem as práticas a partir das diretrizes elaboradas por um grupo pensante.

Segundo Gómez (1997) importância do engajamento do educador nos processos de mudança, o incentivo a grupos impulsionadores, a existência de intercâmbios docentes, o respeito às contradições e a reflexão crítica contínua são princípios significativos que merecem destaque. Isso implica em reconhecer que o "lugar" de atuação do professor interfere em sua postura profissional, e, por conseguinte, na sua inclinação em mudar ou não, incluindo os aspectos externos, como condições de trabalho e os relacionados às políticas educacionais.

Nessa perspectiva, as respostas dos bolsistas de ID são ricas em "pistas" para repensarmos a formação inicial docente. Consideram a articulação teoria e prática como fundamental, mas ponderam que esse processo não é fácil, sentem dificuldade em efetivar aquilo que definem como "fazer diferente" e convivem com certo alheamento da universidade frente ao cotidiano da escola. 


\section{EDUCAÇÃO, ARTES}

VOLUME 11, NÚMERO 1, Ano 2015

E INCLUSÃO

ISSN 1984-3178

Representam o discurso de um grupo de jovens entusiastas por uma educação de maior qualidade e se colocam a disposição desse movimento, mas também já acenam o receio de adiante serem "vencidos" e se inserirem numa, muitas vezes rotina pessimista e comodista. São depoimentos repletos de questionamentos, expectativas e esperança, mas também de angústias e incertezas. Nada muito diferente do que temos ouvido, visto e lido, porém quando são oriundos de pessoas prestes a adentrar na vida profissional, trazem alguns alertas, merecedores de maior atenção por parte de várias instâncias, como gestores da educação, agências formadoras, e de todos/as que têm alguma participação ou atuação nas políticas públicas de formação.

Diante das análises realizadas constatou-se que o PIBID tem tido um efeito bastante positivo e pode, em conjunto com outros programas e ações, compor uma importante iniciativa na construção de novas possibilidades de formação docente vinculada às demandas da Educação Básica, na integração escola e universidade, na valorização da carreira de professor e na conquista da profissionalidade docente. Quiçá seja o programa seja forte os suficiente para junto com outras alternativas e medidas políticas possam manter e expandir o encantamento expresso pela bolsista (R7): “O contato com a sala de aula, com a escola, enfim com o processo ensino aprendizagem dos alunos é o que mais me encanta. O Programa proporciona você se sentir seguro ante a experiência de ser professor."

\section{Referências}

ARROYO, M. Ofício de mestre: imagens e autoimagens. Petrópolis: Vozes, 2000.

BARDIN, L. Análise de conteúdo. Lisboa, Portugal; Edições 70, LDA, 2009.

BRASIL, Coordenadoria de Aperfeiçoamento de Pessoal de Nível Superior (CAPES). Edital 01/2011 e Portaria 260 de dezembro de 2010.

CUNHA, Maria Isabel da. A docência como ação complexa: o papel da didática na formação de professores. IN: ROMANOWSKI, Joana P. (e outros). Conhecimento local e conhecimento universal: pesquisa, didática e ação docente. Curitiba: Champagnat, 2004. (XI ENDIPE, p. 31-42) 


\section{EDUCAÇÃO, ARTES E INCLUSÃO}

VOLUME 11, NÚMERO 1, Ano 2015

FRANCO, Maria Laura P. B. Análise de conteúdo. Brasília: Plano Editora, 2003.

FREIRE, Paulo. Pedagogia da esperança. São Paulo: Editora Paz e Terra, 1992. , Paulo. Cartas a Cristina. São Paulo: Editora Paz e Terra, 1974

GÓMEZ, Angel Pérez. O pensamento prático do professor: a formação do professor como profissional reflexivo. IN: NÓVOA, António (org.). Os professores e a sua formação. Dom Quixote: Lisboa, 1997. p.93-114.

MARTINS FILHO, Altino José et al. Infância plural: crianças do nosso tempo. Porto Alegre: Mediação, 2006, 120p.

NÓVOA, António. Os professores e o "novo" espaço público da educação. IN: TARDIF M. e LESSARD, C. (org.) O ofício de professor: história, perspectivas e desafios internacionais. Petrópolis, RJ: Vozes, 2008. p. 217-233.

Professores: imagens do futuro presente. Lisboa: Educa, 2009.

TARDIF, Maurice. Saberes docentes e formação profissional. Petrópolis: Vozes, 2002.

TARDIF, Maurice; LESSARD, Claude. As transformações atuais do ensino: três cenários possíveis na evolução da profissão de professor? IN: TARDIF M. e LESSARD, C. (org.) $\mathbf{O}$ ofício de professor: história, perspectivas e desafios internacionais. Petrópolis, RJ: Vozes, 2008. p.255-277.

O trabalho docente: elementos para uma teoria da docência como profissão de interações humanas. Rio de Janeiro: Vozes, 2007.

PERRENOUD, Philippe. Ensinar: agir na urgência, decidir na incerteza. Porto Alegre: Artmed Editora, 2001.

SOUZA, Elizeu C. de. A vida com histórias de vida: apontamentos sobre a pesquisa na formação. IN. IN EGEERT, Edla (e outros). Trajetórias e processos de ensinar e aprender: didática e formação de professores. Livro 1. Porto Alegre: EDIPUCRS, 2008. p. 135-154.

ZEICNHER, Kenneth $M$. Uma análise crítica sobre a "reflexão" como conceito estruturante na formação docente. IN: Educação e Sociedade, Campinas, vol. 29, n. 103, p. 535-554, maio/ago. 2008. 